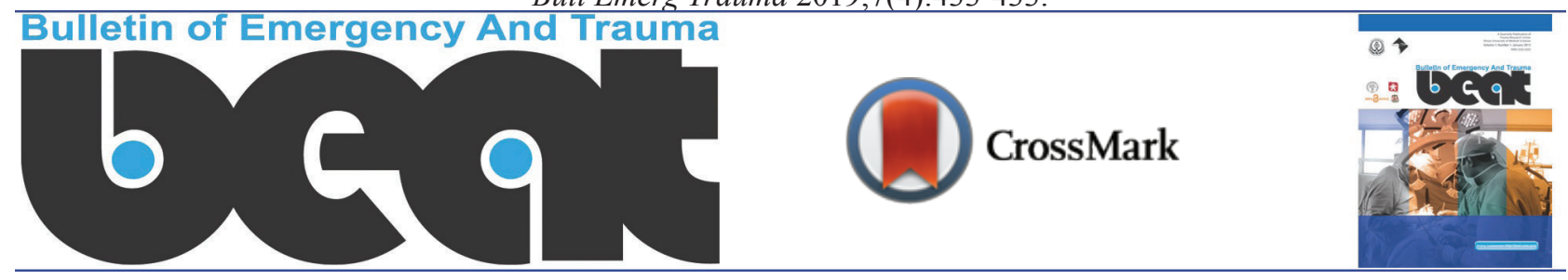

\title{
Erratum: Correction of Mortality Outcome Parameter
}

\author{
[Ahl R, Cao Y, Geijer H, Taha K, Pourhossein-Sarmeh S, Talving P, Ljungqvist O, Mohseni S]
}

Please cite this paper as:

Ahl R, Cao Y, Geijer H, Taha K, Pourhossein-Sarmeh S, Talving P, Ljungqvist O, Mohseni S. Erratum: Correction of Mortality Outcome Parameter. Bull Emerg Trauma. 2019;7(4):433-433. doi: 10.29252/beat-070418.

In the original article entitled "Prognostic Value of P-POSSUM and Osteopenia for Predicting Mortality After Emergency Laparotomy in Geriatric Patients" [1] which was published in July 2019 issue of the journal, there was an error in the specified mortality outcome in the manuscript. The published version describes 30-day mortality, however, the correct outcome measure should be 90-day mortality throughout the article. The article has been corrected accordingly online.

\section{References}

1. Ahl R, Cao Y, Geijer H, Taha K, Pourhossein-Sarmeh S, Talving P, Ljungqvist O, Mohseni S. Prognostic
Value of P-POSSUM and Osteopenia for Predicting Mortality After Emergency Laparotomy in Geriatric
Patients. Bull Emerg Trauma. 2019;7(3):223-31. 